\title{
Opposing Indirect Effects of Domestic Herbivores on Saltmarsh Erosion
}

\author{
Jordi F. Pagès, ${ }^{1 *}$ Stuart R. Jenkins, ${ }^{1}$ Tjeerd J. Bouma, ${ }^{2}$ Elwyn Sharps,,${ }^{1,3,4}$ \\ and Martin W. Skov ${ }^{1}$
}

\begin{abstract}
${ }^{1}$ School of Ocean Sciences, Bangor University, Menai Bridge, Anglesey, UK; ${ }^{2}$ Department of Estuarine and Delta systems, Royal Netherlands Institute for Sea Research (NIOZ), Utrecht University, P.O. Box 140, 4400 AC Yerseke, The Netherlands; ${ }^{3}$ RSPB Centre for Conservation Science, RSPB, The Lodge, Sandy, Bedfordshire, UK; ${ }^{4}$ NERC Centre for Ecology and Hydrology, Environment Centre Wales, Deiniol Road, Bangor, Gwynedd, UK
\end{abstract}

\begin{abstract}
Herbivores can sometimes influence the geomorphology of landscapes, particularly in systems dominated by hydrology. Salt marshes deliver globally valuable benefits, including coastal protection, yet they sometimes rapidly erode. Triggers for erosion are often unknown, but livestock grazing is a suspected cause in many regions of the world where agricultural use of saltmarshes is pervasive. To understand the influence of grazing on saltmarsh erosion, we sampled the plant community, soil chemistry and soil mechanical properties along 2-5 creeks in grazed and ungrazed marshes. Erosion was quantified as: (1) the rates of erosion of extracted soil-plant cores in a hydrological flume and (2) the number of erosional break-offs ('slump blocks') per creek. We found that domestic herbivores influenced saltmarsh geomorphology via two indirect and opposing pathways: one involving soil mechanical properties
\end{abstract}

and the other mediated by plant traits and bare soil cover, all within a soil physico-chemical environment. The net effect of grazing results in a reduction in saltmarsh lateral erodibility and thus an increase in marsh resilience. Our results highlight the role of herbivores not only as controllers of the flow of energy and materials through the trophic web, but also as modifiers of the abiotic environment. Managers and scientists must remain vigilant to both the obvious direct and the more nuanced indirect pathways, which can influence grazed ecosystems. This study calls for a closer look to the biological side of the equation when assessing biogeomorphic feedbacks and plant-soil-animal interactions.

Key words: cattle; coastal erosion; creek; geomorphology; movement; plant-soil-animal interactions; sheep; structural equation models.
Received 18 July 2018; accepted 28 October 2018; published online 30 November 2018

Electronic supplementary material: The online version of this article (https://doi.org/10.1007/s10021-018-0322-5) contains supplementary material, which is available to authorized users.

Author contributions JFP, MWS, SRJ and TJB conceived the ideas and designed methodology; JFP and ES collected the data; JFP analysed the data; JFP and MWS led the writing of the manuscript. All authors contributed critically to the drafts and gave final approval for publication. *Corresponding author; e-mail: j.pages@bangor.ac.uk

\section{INTRODUCTION}

Herbivores are increasingly recognised as potential modifiers of entire food webs by initiating powerful indirect effects (Foster and others 2014), often exceeding the direct consequences of flows of materials and energy from plants to herbivores (Hobbs 1996). Simultaneously, many large herbivores have been acknowledged as ecosystem engineers, ultimately influencing the abiotic environment in both terrestrial (Jones and others 1994; Beschta and Ripple 2006) and aquatic sys- 
tems (Bakker and others 2015). This places large herbivores, not merely as outputs of ecosystems, but as important regulators of biotic and abiotic processes, even capable of controlling the switch of ecosystems (sensu Hobbs 1996) between alternative stable states (Silliman and Ziemann 2001; Christianen and others 2014).

Large herbivores are known to influence the evolution of landscape-level topographical features (that is, geomorphology) in semi-natural rangelands (reviewed by Trimble and Mendel 1995), human-modified croplands (reviewed by Hamza and Anderson 2005), and particularly in ecosystems dominated by hydrology, such as riparian areas (Beschta and Ripple 2006) and pasturelands in humid regions (Trimble and Mendel 1995). Herbivores may influence geomorphology via two main processes (van Klink and others 2015): (i) defoliation and (ii) soil trampling. Defoliation by herbivores might indirectly increase soil erosion: in grasslands, defoliation reduces plant canopy heights and plant cover, both of which can accelerate the erosional force of flowing water and, thereby, the suspension and export of soil particles during rainfall and run-off (Mwendera and Saleem 1997; Russell and others 2001); defoliation of woody vegetation may reduce the role of plant communities in slowing down or preventing streambank erosion along river channels (Simon and Collison 2002; Murray and Paola 2003) and rates of channel migration in floodplain systems (Hickin 1984; Micheli and Kirchner 2002). Although studies have traditionally focused on the geomorphological effects of herbivores via defoliation, recently, the multifaceted effects of soil trampling have received increasing attention (Sørensen and others 2009; Elschot and others 2013; Schrama and others 2013; van Klink and others 2015).

Trampling can induce both direct and indirect geomorphological effects. Herbivores disturbing riparian areas may directly modify river channels and cause erosional break-offs of river and creek banks (Trimble and Mendel 1995; Magilligan and Mcdowell 1998; Beschta and Ripple 2006). Livestock crossing of channelled systems is particularly destructive, since the force of one or two hooves supporting the entire weight of a large animal can actually shear off slices of bank material into the stream (that is, slump blocks, Figure S1) (Trimble and Mendel 1995). Trampling by herbivores might also induce a diversity of indirect effects, such as reduced soil water infiltration rates, which result in increased run-off and overland flow (Stavi and others 2009) that further promote erosion
(Mwendera and Saleem 1997). In contrast, through the application of pressure on the soil surface, trampling by hoofed animals directly increases soil compaction and increases soil bulk density (Trimble and Mendel 1995; Stavi and others 2009; Schrama and others 2013), which might reduce erosion rates. In this study, we investigate the direct and indirect pathways whereby grazers influence erodibility in salt marshes, and whether the net overall effect of livestock results in an increase or a reduction in saltmarsh erodibility.

Salt marshes are areas vegetated by herbs, grasses or low shrubs, bordering saline water bodies (Adam 1990), typically located at the boundary between land and sea and dominated by tidal hydrodynamic forces. Their establishment and persistence stems from strong positive feedback between vegetation growth, hydrodynamics and soil accretion (Van de Koppel and others 2005; D'Alpaos 2011). As inundation stress builds up, through sea level rise (IPCC 2013) or the frequency of storm events rises (at least in some regions, for example, Lowe and others 2009), this biogeomorphic feedback is increasingly critical for marsh stability. Many studies report extensive loss in saltmarsh area (Cooper and others 2001; Kearney and others 2002; Huey and others 2012; Murray and others 2014). Where instability arises, marshes may shift into an alternative stable state, where all vegetation and associated valuable functions are lost (Wang and Temmerman 2013; van Belzen and others 2017). In some cases, saltmarsh loss (or lack of recovery) has been partly attributed to overgrazing by snails and periwinkles, or crab and polychaete bioturbation (Paramor and Hughes 2004; Silliman and others 2007; Daleo and others 2014), highlighting the potentially relevant role of herbivores in the stability of these ecosystems.

Although the direct and indirect effects of herbivores on geomorphology have been widely acknowledged for terrestrial (for example, Mwendera and Saleem 1997; Russell and others 2001; Stavi and others 2009) and riparian systems (Magilligan and Mcdowell 1998; Beschta and Ripple 2006, 2016), fewer studies have addressed this issue in the marine and coastal environment (but see Christianen and others 2013; Elschot and others 2013; Bakker and others 2015 and references therein), and to our knowledge, no study has explicitly addressed the mechanisms whereby herbivores may influence saltmarsh erodibility. This is particularly concerning given that marshes, which can collapse into unvegetated alternative stable states, are widely used for livestock grazing (Nolte and others 2015; Davidson and others 2017) 
and that it is widely accepted that the geomorphological effects of herbivores are especially accentuated in fine-textured, wet, poorly drained soils (Trimble and Mendel 1995).

In this study, to clarify the role of livestock grazing on saltmarsh erodibility, we first use cattle movement data to show that livestock use mid-tolow marsh elevations, where erosion risks are pertinent to marsh long-term lateral change. We then analyse the plant community, soil chemistry and soil mechanical properties of grazed and ungrazed marshes in Wales (western Britain) to determine the potential effects of grazing on saltmarsh erodibility. We restrict our sampling to creek banks as representatives of marsh edges where lateral erosion occurs. We take advantage of previous knowledge of the system to design a conceptual meta-model (Figure 1), which was used as the basis for testing whether the data sampled in the field fit the following hypotheses: (1) livestock grazers increase erosion directly, by trampling on cantilever creek edges and breaking creek banks (producing 'slump blocks', Figure S1) (path 1, Figure 1); in addition, (2) livestock further increase erosion rates indirectly via defoliation (path 2, Figure 1). In contrast, (3) trampling by livestock decreases erosion rates indirectly by influencing the mechanical properties of the soil (that is, compaction) (path 3, Figure 1). Finally, we assume that (4) livestock grazing will modify other soil physico-chemical properties (for example, $\mathrm{pH}$, moisture, organic matter), which in turn might influence the rest of these pathways (path 4, Figure 1).

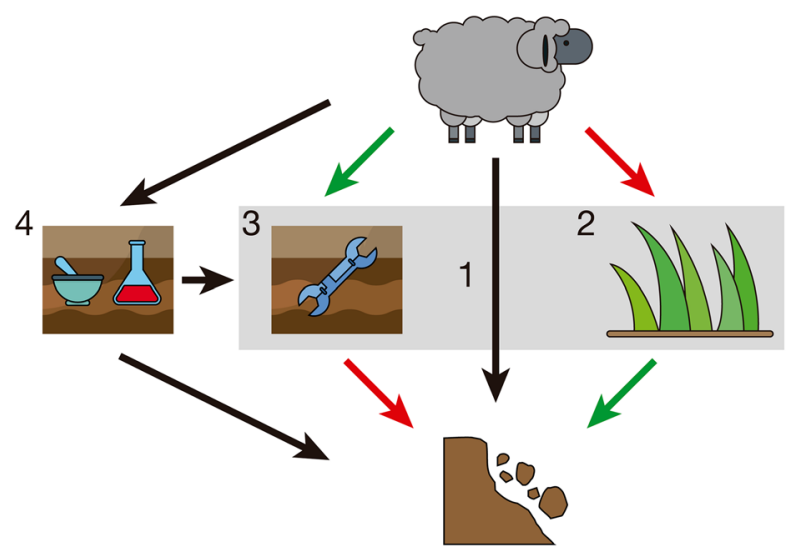

Figure 1. Conceptual meta-model that informed and served as the theoretical background for the SEMs (Grace and others 2010). This meta-model addresses the hypotheses posed at the end of Introduction.

\section{Materials AND Methods}

\section{Livestock Utility Distributions}

To assess whether livestock use the areas around creek banks, with potential consequences for marsh lateral erosion, we analysed a data set of GPS-collared cattle from two salt marshes, on the eastern coast of Britain (RSPB Frampton Reserve) (total $n=12$ ). This represented $10.4 \%$ of the cattle present on the marshes, and as cattle are herding animals, we assumed that the distribution of this sample would be representative of the whole herd (Sharps and others 2017). GPS loggers were constructed from SiRFstarIV GSD4e-T GPS processor chipsets (recorded accuracy $=2.5 \mathrm{~m}$ ) and attached to cattle using a neck collar. Between May and October 2013, GPS loggers recorded a position every $20 \mathrm{~min}$ when satellite signals were available. The loggers were retrieved at the end of the grazing season. Due to battery life, some loggers stopped earlier than planned, but approximately $50 \%$ of the loggers per saltmarsh recorded the entire period.

The package move (Kranstauber and Smolla 2016) in $\mathrm{R}$ was used to estimate individual animal utility distributions (UDs) with the dynamic Brownian bridge movement models (DBMM, Kranstauber and others 2012). UD estimation provides an objective way to define an animal's normal activities (Powell 2000). UDs are probability density functions that provide the animal's probability of use for each cell (that is, pixel) of a given grid. DBBMM interpolates intermediate points between detections assuming a Brownian movement model and generates a density surface based on these (Kranstauber and others 2012). Location error was set as $10 \mathrm{~m}$, based on the average detection error of the GPS loggers. Contour lines for the area were drawn for 50 and $95 \%$ of probability of animal use. All individual UDs were pooled into a population level UD for each of the two marshes where animals were collared.

\section{Livestock Effects on Marsh Erosion}

\section{Study Sites and Design}

To assess the importance of grazing on salt marsh erosion rates and creek slumping, we selected seven salt marshes in the west coast of Wales (UK), three of which were grazed and four ungrazed (Figure 2, Table S0). All sites were sampled during June-August 2016. Marshes were mostly grazed by sheep, although one of the sites (Dyfi North, Fig- 


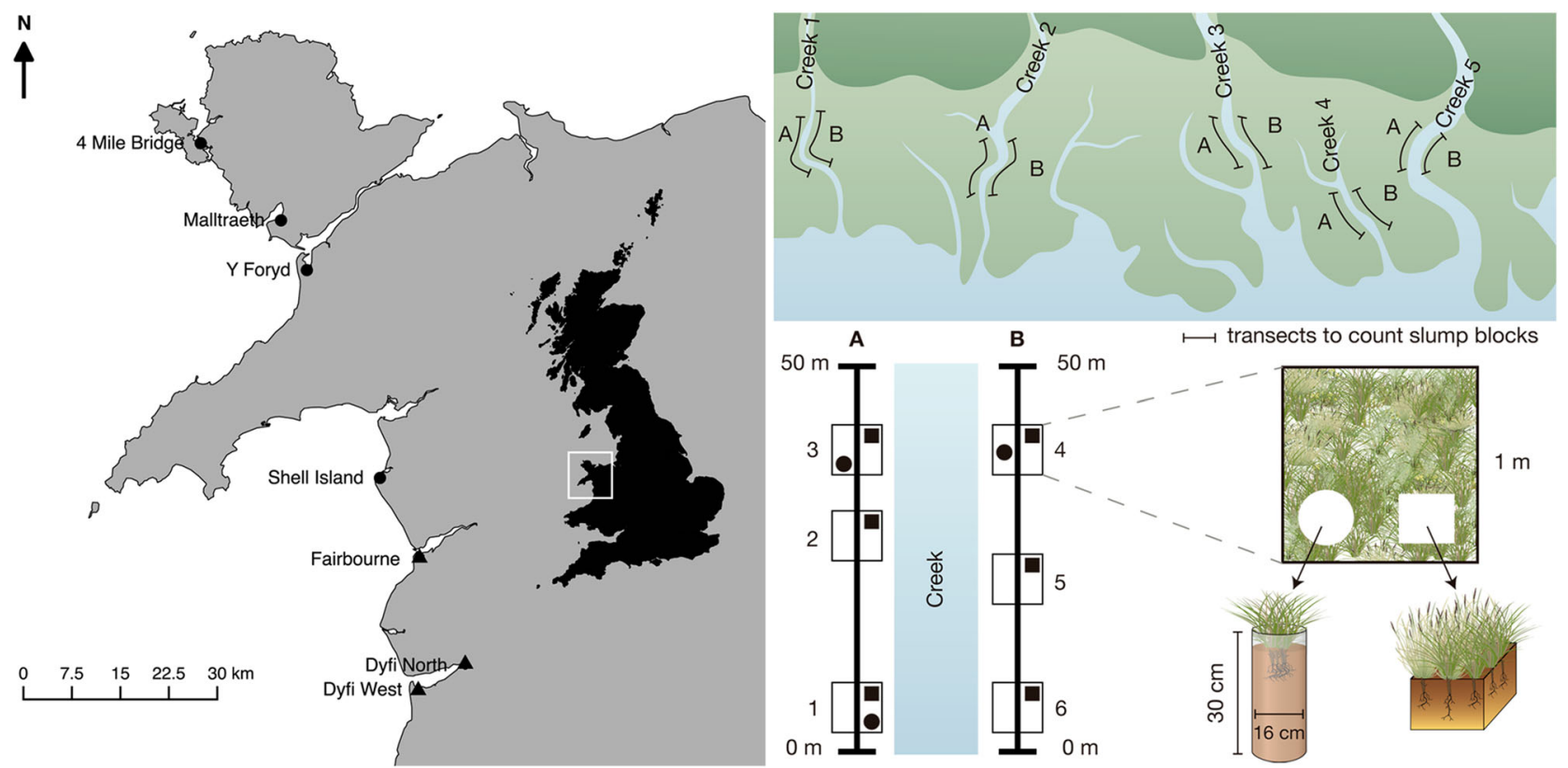

Figure 2. Study sites and sampling design. Study sites were situated on the Western coast of Wales, on the West of Great Britain (see inset on the map). We sampled four ungrazed salt marshes (filled circle) and three grazed salt marshes (filled triangle). In each marsh, we laid 2-5 transects $(50 \mathrm{~m})$ to assess the abundance of 'slump blocks' and placed six $1 \times 1 \mathrm{~m}$ quadrats. In all six quadrats, we estimated soil shear stress, plant species composition, canopy height, plant abundance (\% cover) and extracted a portion of soil to assess $\mathrm{pH}$, salinity and organic matter. In three of these quadrats, a soil erosion core was additionally extracted.

ure 2, Table S0) additionally had a few cattle. Grazed sites were stocked at 0.7-3.4 LSU ha ${ }^{-1} \mathrm{y}^{-1}$ (LSU: livestock units, Table S0), and the grazing regime had not changed for at least 30 years (Kingham 2013). To minimise contextual variation, sampling focused on the mid-marsh (1.3$2.5 \mathrm{~m}$ above mean sea level), and to areas within $1 \mathrm{~m}$ of creek edges, where erosion risk was highest. All study sites were macrotidal with very similar tidal ranges (Table S0). Most study sites were dominated by Puccinellia maritima (Huds.) Parl. or by Juncus gerardii Loisel (SM13 and SM16 communities from the British Vegetation Community classification, Rodwell 2000). We sampled $50 \mathrm{~m}$ stretches of creek in 2-5 creeks per site, depending on marsh size (see Figure 2). Both creek banks were sampled. The abundance of soil blocks detached from the creek edge ('slump blocks', Figure S1) was recorded and used as a response variable at the creek level. The rest of response variables (outlined below) were sampled within $1 \times 1 \mathrm{~m}$ quadrats per creek. We used a differential GPS (Leica GS08 GNSS system) to measure quadrat elevation and latitude-longitude coordinates to within $\pm 0.05 \mathrm{~m}$. Elevation was recorded in metres relative to Ordnance Datum Newlyn (ODN) and used as a proxy for tidal inundation.

\section{Soil Erosion Cores}

Within three quadrats per creek, one large cylindrical sediment core $(16 \mathrm{~cm}$ diameter, $30 \mathrm{~cm}$ height) including above-ground vegetation was collected (Figure 2). Soil erosion rate was quantified following Ford and others (2016). A $10-\mathrm{cm}$ wide opening was cut along the length of each core (see Figure S2). The core was then placed horizontally, with the underlying soil exposed to erosion, under a recirculating overshot-weir flume for $\mathrm{l} \mathrm{h}$, using two different water erosion forces over the sample-30 min at low [61 Pa] and $30 \mathrm{~min}$ at high pressure [146 Pa]. The stagnation pressure associated with flow being forced to change direction directly over the core caused sediment to be eroded (see Figure S2), representing side impact on the margin of a vegetated bank by waves and currents (Ford and others 2016). We measured core weight at 0 (initial weight), 15, 30, 45 and $60 \mathrm{~min}$, and we calculated soil erosion rate as the mass lost over the 0-60-min interval and expressed it as $\%$ mass loss $\min ^{-1}$.

\section{Vegetation Characteristics}

Above-ground vegetation cover, bare soil cover, species composition and canopy height (mean of 10 
observations/quadrat) were observed in six quadrats per creek (Figure 2). We estimated plant biodiversity (Shannon-Wiener index, H) based on species cover and used Tablefit v2.0 (Hill 2015) to assign each quadrat to a British National Vegetation Community (NVC, Rodwell 2000). Root dry biomass $\left(60^{\circ} \mathrm{C}, 72 \mathrm{~h}\right)$ was obtained from erosion cores $(n=3 /$ creek) after washing away remaining sediment. While in the flume, cores were enclosed within a mesh to recover any detached roots, thus avoiding an underestimation of root biomass (see Figure S2). Erosion cores were $30 \mathrm{~cm}$ deep, which captures the majority of plant roots for most common saltmarsh plant species (Ford and others 2016).

\section{Soil Characteristics}

Within six quadrats per creek, we assessed soil compaction by measuring soil penetration resistance $\left(\mathrm{kg} \mathrm{cm}^{-2}\right)$ with a hand-held penetrometer (ELE international) (mean of 5 points/quadrat) and sub-surface soil strength using a soil shear vane (ELE international) (mean of 3 points/quadrat). Within six quadrats per creek, $\mathrm{pH}$ and electrical conductivity were measured (Jenway 4320 conductivity meter) from about $10 \mathrm{~g}$ soil samples taken from the top $10 \mathrm{~cm}$ of soil, which had been diluted 1:2.5 by volume with deionised water. We also took soil bulk density samples from the top $20 \mathrm{~cm}$ of soil (avoiding areas rich in roots) in all six quadrats, using a known-volume stainless-steel ring $(3.1 \mathrm{~cm}$ height, $7.5 \mathrm{~cm}$ diameter). The sediment from bulk density samples was used to estimate soil organic matter content from loss on ignition $\left(375^{\circ} \mathrm{C}, 16 \mathrm{~h}\right)$ and grain size. Grain size was classified into 33 size fractions from 0.2 to $2000.0 \mu \mathrm{m}$ (Wentworth scale) using a Malvern Particle Sizer 2000, after organic matter digestion with hydrogen peroxide (conducted at the Geography Science Laboratories of the Department of Geography, University of Cambridge).

\section{Statistical Analysis}

To evaluate both the direct and indirect effects of grazing on saltmarsh erosion, we analysed our data set using two approaches: (i) (generalised) linear mixed-effects models ([G]LMMs) and (ii) structural equation models (SEMs). While (G)LMMs can only determine the influence of direct effects on response variables, SEMs are perfectly suited to assess the existence of indirect effects (mediation) on the response. Moreover, SEMs allow us to utilise observational data for evaluating causal hypotheses (Grace 2006). An important consideration in causal modelling is that it combines theoretical a priori knowledge with the statistical analysis of data (Grace and others 2015). In consequence, paths featuring in the theoretical meta-model (Figure 1) were always included in the initial SEM, regardless of whether the variable had been dropped or retained as significant in the (G)LMMs (Grace and others 2015). All analyses were run in $R$ ( $R$ Development Core Team 2017) and the entire (G)LMM and SEM procedures are included as a supplementary $\mathrm{R}$ script (Livestock\&Erosion_GLMMESEM_analyses.R).

\section{Mixed-Effects Stepwise Modelling}

We fitted separate (G)LMMs to the following response variables: soil core erosion rates, slump block abundance, root biomass, plant cover, bare soil cover, soil shear stress, soil bulk density, soil $\mathrm{pH}$, plant diversity, soil electrical conductivity and plant canopy height. The complete list of predictor variables introduced in the models as fixed effects included: soil organic matter, soil shear stress, soil hardness, bare soil cover, elevation, grazing, plant diversity, soil grain size and soil $\mathrm{pH}$. As evident from the lists above, some variables acted as responses or predictors in different models. For the complete list of best-selected (G)LMMs, along with model specifications, please refer to Table S1. We used AIC and log-likelihood ratio tests to evaluate the need to include the categorical random effects 'site' (7 levels), 'creek' (between 2 and 5 levels nested in 'site') and 'plant community' of the quadrat (14 levels). When necessary, variables were transformed to ensure normality of model residuals (see Table S1). For each model, we graphically checked the variance of the residuals to confirm there were no signs of heterogeneity. The sample size of the models was different according to the variables included and ranged from 66 to 144 (that is, models with the lowest sample size were those including variables related to sediment cores [erosion rates, root biomass], since only 3 cores were taken per creek [see sections above]). We performed marginal Ftests with univariate analysis of deviance (Zuur and others 2009) to investigate the effects of predictor variables in each model. We used the information gathered during (G)LMM analysis to inform SEM building, particularly regarding the specification of their random effects (see below) (Deguines and others 2016; Lefcheck 2016). In addition, (G)LMMs were used to visualise the shape of the relationships between response variables and the relevant direct effects (for 
example, see Figures 4B, C, 5B, C and Supplementary Materials).

\section{Structural Equation Models}

Following the preliminary mixed-effects analysis, and the critical consideration of the selected models mentioned above, we used the $\mathrm{R}$ package piecewise SEM (Lefcheck 2016) to produce two SEMs: one to evaluate the links between local, physico-chemical, biological variables and soil core erosion rates $(n=77)$ and the other to evaluate the relationship of those same components and creek slumping $(n=144)$. Piecewise SEM allows for a relaxation of the restrictive assumptions that apply when we work with covariance matrices, which means we can include random effects and use generalised linear models (Grace and others 2015). Shipley's test of d-separation (Shipley 2009) was used to assess the overall fit of the SEM and whether paths were missing from the model. Following recommendations from Grace and others (2015), we added paths that were suggested by Shipley's test whenever a biologically plausible connection between variables existed, based on our knowledge of the system. Care was taken to keep the amount of path additions to a minimum in order to avoid overfitting the model (Grace 2006) and to ensure that the ratio of sample size to the number of estimated paths was greater than five (Grace and others 2015). That is the reason for the lower number of variables included in the SEM linking grazing and soil core erosion rates, given the smaller sample size of this data set $(n=77)$.

\section{RESULTS}

\section{Livestock Utility Distributions}

The two GPS-logged cattle populations showed similar movement patterns (Figure 3). Although both groups used the landward edge of the marsh and other areas with high elevations more intensively, they also used the mid-marsh and even the lower edge of the marsh, as shown by their utility distributions (especially the southern population [dark blue shading], Figure 3). By overlapping the population UDs with an aerial photograph from these marshes, we can see that both populations used areas with high creek density, and areas that implied crossing creeks (Figure 3).

\section{Livestock Effects on Marsh Stability}

None of our best-selected (G)LMMs included an effect of grazing on marsh edge stability (erosion rates and slump block abundance), highlighting that if grazing had any effect, it would be mediated by other variables and would only be determined by SEMs. Specifically, (G)LMMs showed that erosion rates from soil cores decreased with shear stress and soil organic matter content (Table S1, Figure 4B, C); while slump block abundance increased with bare soil cover (Figure 5B, Table S1) and shear stress (Table S1), although the significance of these latter effects was relatively low considering the complexity of this model (GLMM with negative binomial distribution). Table S1 gives a complete list of best-selected (G)LMMs for each response variable, along with their modelled random structure. (G)LMMs allowed us to determine the most relevant fixed and random variables affecting each response. This information was useful to build the initial SEM model. (G)LMMs were also useful to discard response variables due to their complex multidimensional nature (for example, bulk density, Table S1, Figure S4), or low explained variance (for example, root biomass, Table S1, Figure S5).

Our final SEMs adequately fitted the data (Fisher's $\quad C_{\text {erosion_rates }}=11.33, \quad P_{\text {erosion_rates }}=0.332$; Fisher's $C_{\text {slumping }}=41.57, P_{\text {slumping }}=0.174 ;$ Fisher's $C$ values measure the magnitude of discrepancy between model and data, and thus, $P>0.05$ indicates no significant lack of fit between model and data). Compared to the hypothesised initial SEM for soil erosion cores (Fisher's $C_{\text {erosion_rates }}=$ $49.5, P_{\text {erosion_rates }}=0$ ), just one path addition was required. The initial SEM for slump block abundance $\left(\right.$ Fisher's $C_{\text {slumping }}=98.15, P_{\text {slumping }}=0$ ) required four path additions. Both SEMs displayed high predictive power for their response (endogenous) variables (between $R^{2}=54-91 \%$, Table S2B, E). However, for some response variables (that is, plant diversity, \% organic matter and slump block abundance), the explanatory power of their fixed predictors was very limited (see marginal $R^{2}$, Table S2B, E), and most of the predictive power came from the inclusion of random effects (see conditional $R^{2}$, Table $\left.\mathrm{S} 2 \mathrm{~B}, \mathrm{E}\right)$, revealing the importance of local factors (that is, site, plant community) for these response variables.

In accordance with (G)LMMs, SEMs ruled out any direct effects of grazing on erosion rates or creek slumping (path 1 from Figure 1; see also Figures 4A, 5A). In contrast, we found strong support for an effect of livestock grazing on soil core erosion rates via an indirect effect mediated by soil mechanical properties (path 3 from Figure 1; see also Figure 4A). Grazing strongly increased soil shear stress (high path coefficients, see Table S2A; 


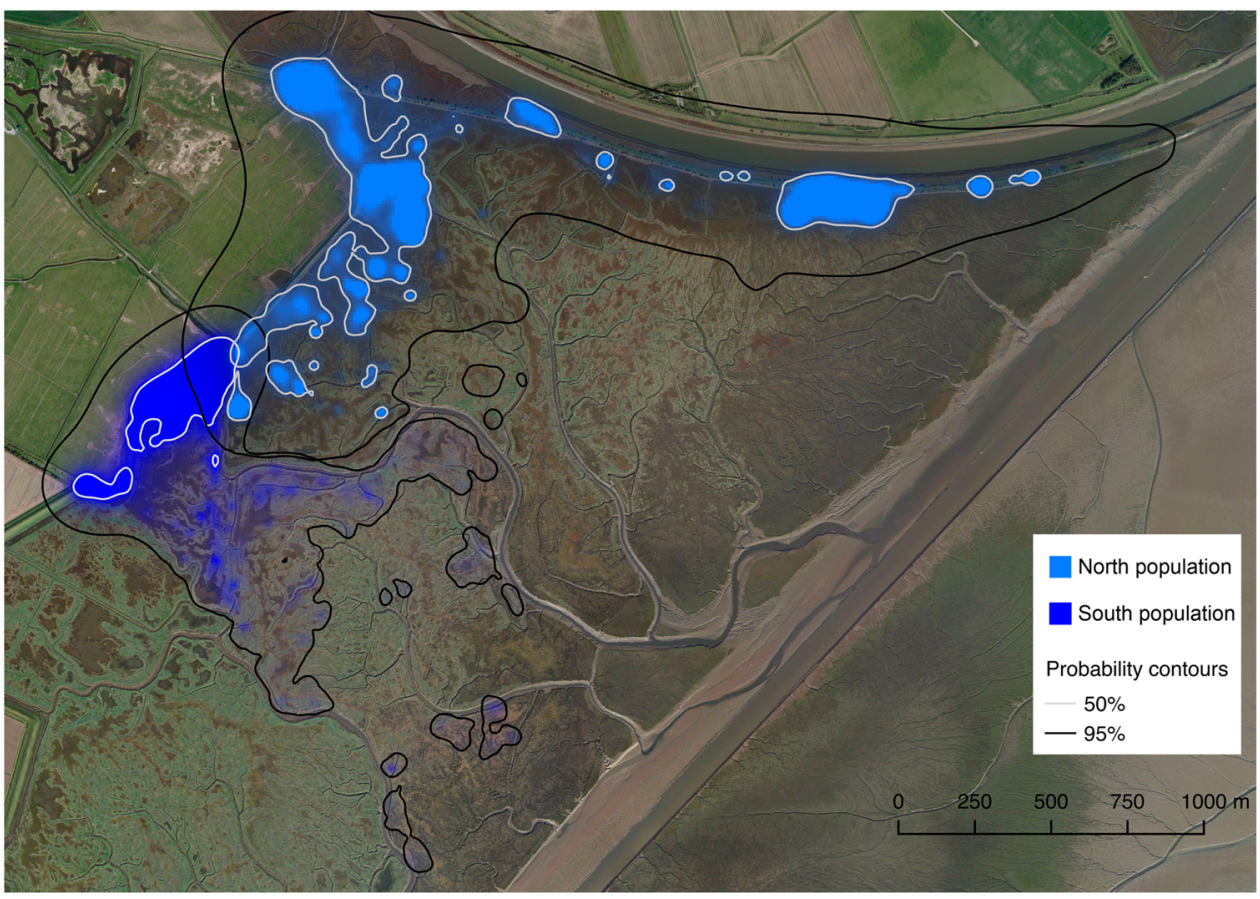

Figure 3. Dynamic Brownian bridge movement model output showing the utility distribution of the four cattle collared in the north marsh and the eight cattle collared in the south site. Note that cattle travelled to the lower edge of the marsh and they frequently crossed creeks (especially in the south site).

see also Figure S3B), a measure of soil compaction, and in turn, shear stress had a negative effect on erosion rates (Figure 4A, B). Therefore, the total indirect effect of grazing was to reduce soil core erosion rates. In contrast, we did not find any evidence of indirect effects on the abundance of slump blocks mediated by soil mechanical properties (Figure 5A).

Although livestock grazing strongly reduced canopy height (Figure 4A, Figure S3D) and root biomass (not included in SEM, but see Figure S5D), we did not find evidence of indirect effects on erosion rates that were mediated via the plant community (path 2 from Figure 1). Nevertheless, we found support for an indirect effect of grazing on the abundance of slump blocks, via plant height and bare soil cover (Figure 5A). Grazing significantly reduced canopy height. Canopy height on its own had a negative direct effect on bare soil cover, and bare soil cover alone had a positive direct effect on the abundance of slump blocks. Thus, the resulting total indirect effect of grazing was to increase creek edge slumping. In parallel, grazing also indirectly affected slumping via plant diversity, canopy and bare soil cover (Figure 5A). Although significant, grazing appeared to have only a limited effect on creek slumping, given the small coeffi- cients of the paths mentioned above (Table S2D). As an example, SEM path coefficients for slump blocks predict that for each $10 \%$ increase in bare soil cover, total slump block abundance will increase by 0.2 blocks per creek.

Grazing did not affect soil physico-chemical properties (path 4, Figure 1). None of the versions of the different SEMs analysed included a significant effect of grazing on $\mathrm{pH}$, organic matter or sand content. Soil organic matter on its own influenced soil mechanical properties (that is, shear stress) and soil erosion rates (Figure 4A, C), but not creek slumping (Figure 5 ). Sand content in the soil had a negative effect on soil organic matter content (Figures 4A, 5A, C), which in turn negatively influenced soil pH (Figure 5A, Figure S3C).

Elevation above sea level, a proxy for tidal inundation, directly affected soil variables, such as organic matter (Figure 5A), bare soil cover (Figure 5A) and soil shear stress (Figure 5A, Figure S3A). In addition, according to the SEM, creeks at higher elevations in the marsh presented a higher degree of creek slumping (Figure 5A), although the effect appears to be somewhat trivial (Table S2D), since for each $1 \mathrm{~m}$ of increase in elevation, creeks would display 0.9 more blocks, whereas the span of elevations sampled was less than $1 \mathrm{~m}$. 

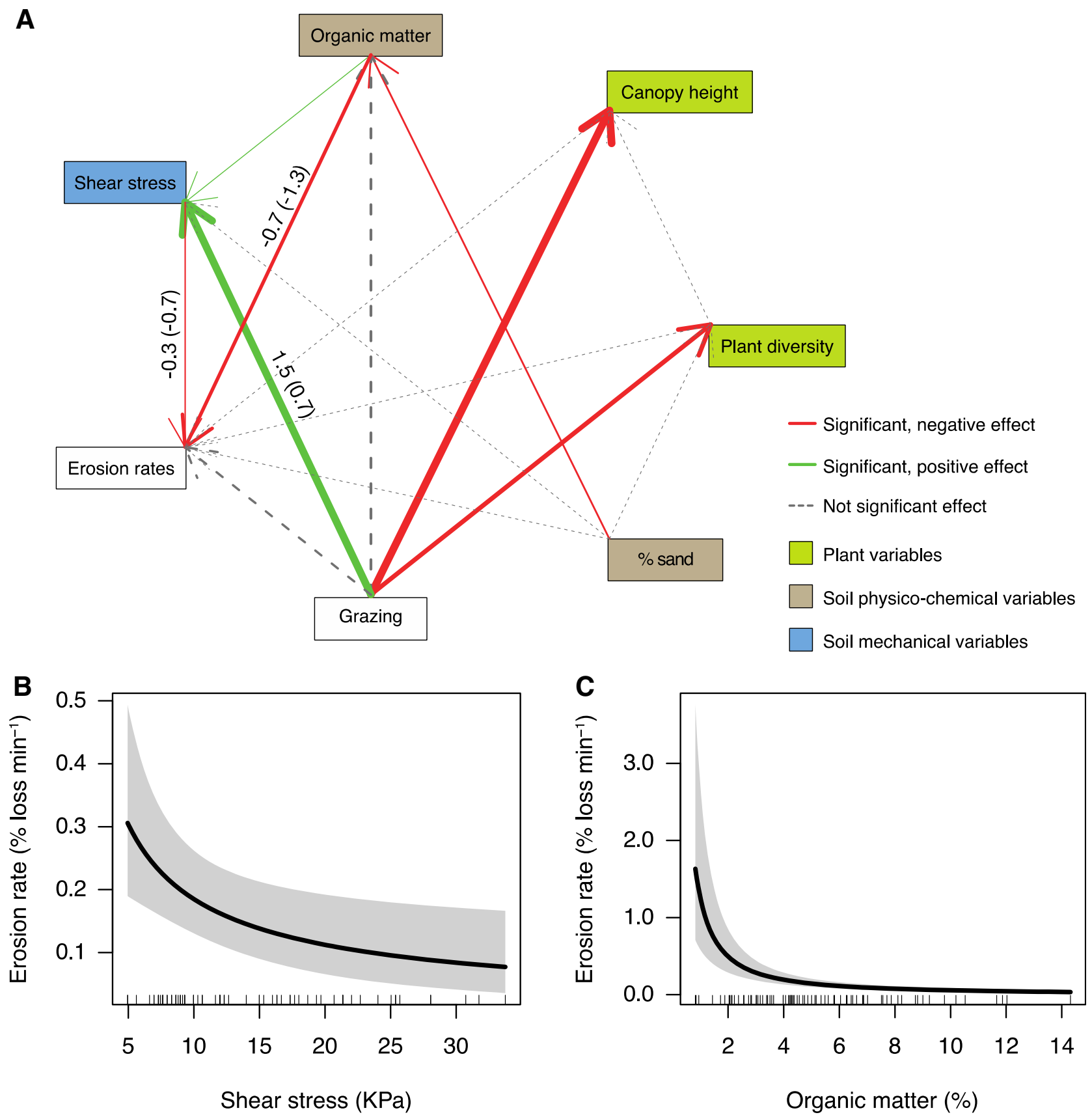

Figure 4. Grazing influenced the erosion rates of soil cores. A Final SEM showing that grazing indirectly reduced erosion rates by directly increasing soil shear stress. Shear stress and \% organic matter had a negative relationship with erosion rates. Standardised and unstandardised coefficients (in brackets) are shown for the most relevant paths (see Table S2A, for the complete list). B Linear mixed-effects model fits, showing the functional form of the negative relationship between soil cores erosion rates and soil shear stress, and $\mathbf{C}$ erosion rates and \% of organic matter in the soil. Solid lines in model fit plots correspond to the fitted values of the model, shaded areas are the 95\% CI around fitted values, and the rug of short lines shows the position of raw data on the $x$-axis.

The SEM describing the relationship between grazing and soil core erosion rates represented our data set more adequately (that is, greater overall fit, strength of path coefficients and predictive power of fixed effects) than the SEM describing the relationship between slump blocks and grazing. Therefore, the mechanisms disentangled with the SEM in Figure 4 are likely the most important ones 


\section{A}

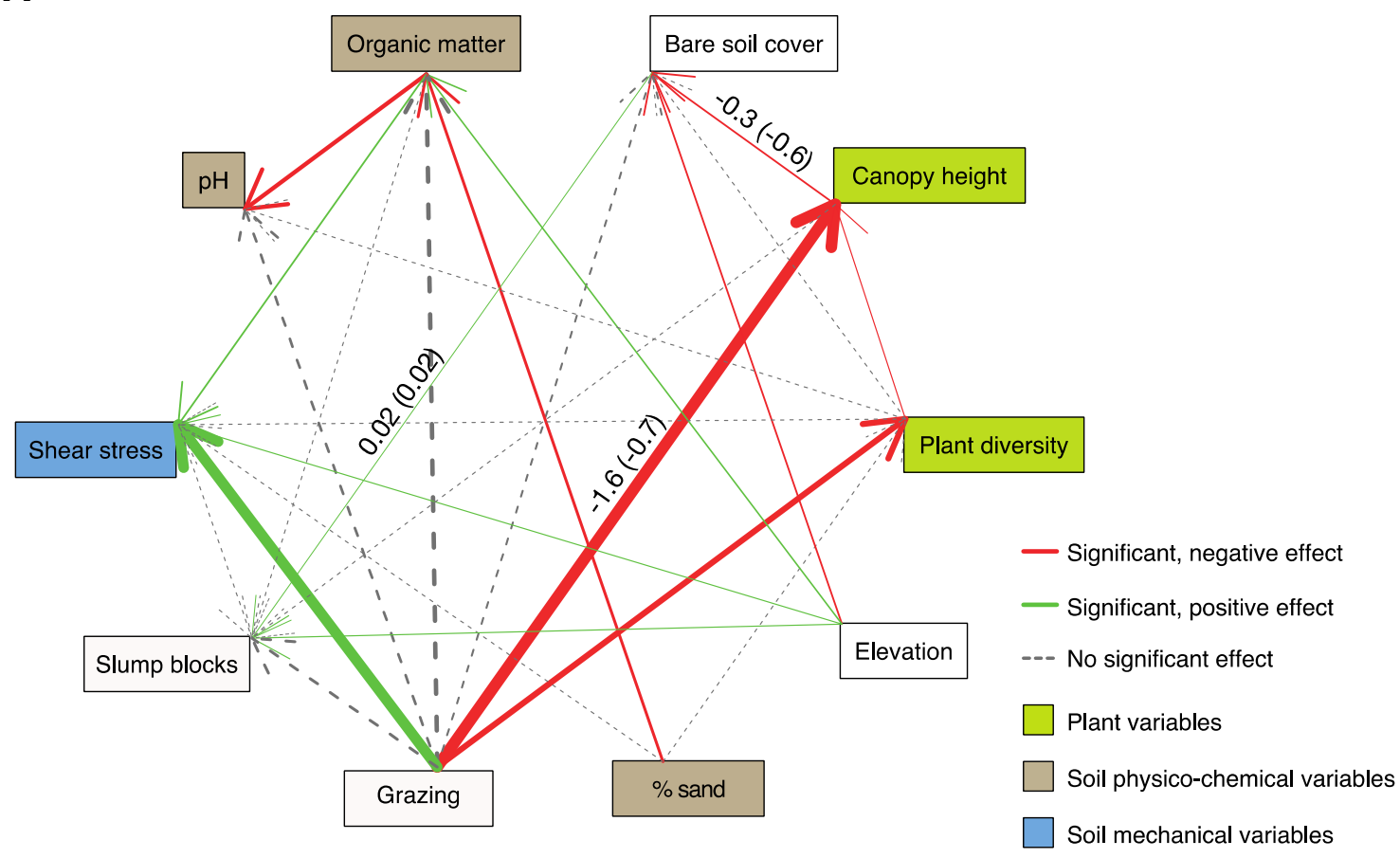

B
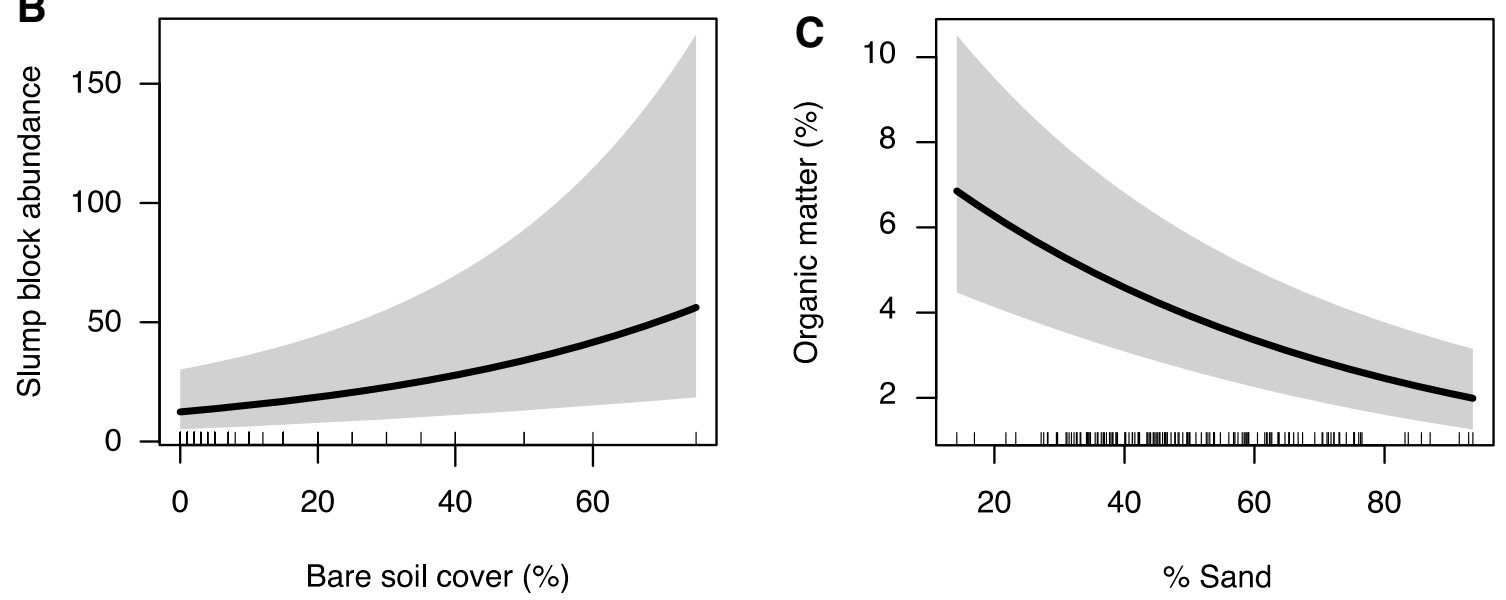

Figure 5. Grazing influenced slump block abundance. A Final SEM showing that the overall net indirect effect of grazing was to increase creek edge slumping via canopy height and bare soil cover. Standardised and unstandardised coefficients (in brackets) are shown for the most relevant paths (see Table S2d, for the complete list). B (G)LMM fits, showing the functional form of the positive relationship between slump block abundance and soil shear stress, and $\mathbf{C}$ organic matter and sand content in the soil. Solid lines in model fit plots correspond to the fitted values of the model, shaded areas are the $95 \%$ CI around fitted values, and the rug of short lines shows the position of raw data on the $x$-axis.

in determining erosion in the salt marshes studied. In contrast, while the mechanisms presented in Figure 5 are significant, they are not strongly explaining slump block abundance (marginal $R^{2}=0.23$ ), implying that local factors (that is, plant community, site) are mainly driving slump block abundance, given the high conditional $R^{2}$ for this response (conditional $R^{2}=0.91$ ).

\section{Discussion}

Our results highlight the role of herbivores not only as controllers of the flow of energy and materials through the trophic web, but also as modifiers of the abiotic environment. We found that domestic herbivores influence saltmarsh geomorphology via two indirect and opposing pathways: one involving 
soil mechanical properties (path 3, Figure 1) and the other mediated by plant traits and bare soil cover (path 2, Figure 1). The relative importance of each of these processes determines the final net effect of livestock grazing on saltmarsh lateral erodibility. In the case of the present data set, path coefficients indicated a dominance of the grazing $\rightarrow$ soil compaction $\rightarrow$ erosion pathway (see results and Table S2A, D). Thus, for the sample of salt marshes studied, with their context-specific soil physico-chemical conditions and their stocking densities, grazing indirectly reduced soil erodibility overall. Interestingly, in contrast to our first hypothesis, and to results from other ecosystems dominated by hydrology (Trimble and Mendel 1995; Mwendera and Saleem 1997), we did not find evidence of direct effects of grazing (through trampling) on saltmarsh erodibility (path 1, Figure 1). The mechanisms disentangled by our path models are relevant to any grazed salt marsh around the world; local factors will only change the coefficients and significance of the different paths identified, which will determine the overall net effect of grazing on salt marsh erodibility.

Our work highlights the importance of herbivores in influencing, not only the biotic components of ecosystems, but also the abiotic environment in which biotic interactions occur. It supports a growing literature that, in recent years, has begun to re-evaluate the importance of herbivores acting as initiators of strong indirect effects through ecosystem engineering (for example, Pringle and others 2007; Prugh and Brashares 2012), ultimately influencing the geomorphology of terrestrial (Trimble and Mendel 1995) and aquatic systems (Bakker and others 2015). In terrestrial habitats, cows and large wild ungulates have been recognised as a major geomorphic agent (Trimble and Mendel 1995). Most terrestrial herbivores have generally been found responsible for an increase in soil compaction as a direct effect of trampling (Bell and others 2011; Schrama and others 2013; van Klink and others 2015), which theoretically should make soils less erodible (Ghebreiyessus and others 1994). However, this has hardly been reported in the scientific literature. In contrast, increased compaction by grazers has been linked to increased erosion due to overland flow (Trimble and Mendel 1995), as a result of decreased porosity and infiltration rates (for example, Mwendera and Saleem 1997; Stavi and others 2009). In freshwater systems, hippopotamuses (Mosepele and others 2009), beavers (Hood and Larson 2015) and semi-aquatic wild ungulates (for example, Naiman and Rogers 1997; Beschta and
Ripple 2006) are known to influence river and pond morphologies. In the marine environment, the evidence is scarcer, but green turtles have been found capable of inducing seagrass habitat collapse into a fine sediment turbid state (Christianen and others 2014), and similarly, dugongs are known to influence the granulometry of their feeding trails with cascading influences to the community of infauna (Skilleter and others 2007). Thus, in contrast to our results, which show that domestic grazers can increase the resilience of salt marshes to erosion (that is, reduce marsh erodibility), both terrestrial and aquatic herbivores have generally been found responsible for an increase in soil erosion/sediment mobility (with the exception of beavers). These discrepancies might be attributed to geomorphic and hydrodynamic differences between salt marshes and the study systems of most zoo-geomorphological studies. Although a wide array of animals has been recognised as geomorphic agents (Butler 1995), the vast majority of work has come from arid rangelands, grazed highlands, sloping croplands and sloping riparian areas (Trimble and Mendel 1995; Hall and others 1999). Unlike these systems, salt marshes are intrinsically less susceptible to overland flow and surface run-off, but respond strongly to lateral currents and wave impacts undercutting overhanging creek and marsh banks (Francalanci and others 2013).

Our findings provide evidence to support anecdotal observations (mainly from Germany) suggesting that grazing could be used as a means to stabilise saltmarsh soils, given the perception of ungrazed salt marshes eroding more easily (Bakker and others 1993). This is the first study in establishing the mechanisms whereby livestock grazing influences saltmarsh erodibility. A preliminary study on the effects of large herbivores (sika deer) on saltmarsh erosion estimated a higher degree of erosion in grazed vs. ungrazed creeks, through analysis of aerial images (House and others 2005). However, the study was not replicated at the site level and the exact mechanisms involved were not determined. Achieving a mechanistic understanding of saltmarsh lateral erosion is important given that salt marshes may shift into an alternative stable state of unvegetated tidal flat (Van de Koppel and others 2005; van Belzen and others 2017), where all vegetation and associated services are lost (Barbier and others 2011) and from which recovery might be lengthy (Van de Koppel and others 2005; D'Alpaos 2011). The coupling between hydrodynamics transporting sediment, plant growth intercepting sediment particles, and the resulting 
increase in soil elevation creates strong positive feedback that drives saltmarsh colonisation (for example, D'Alpaos 2011). It is the very presence of positive feedback that allows for the existence of alternative stable states (Van de Koppel and others 2005; van Wesenbeeck and others 2008; Scheffer 2009). Our results show that herbivores in salt marshes can further add another positive feedback by reducing erodibility, thus allowing the maintenance of surface elevation and improving the conditions for plant growth, which in turn would be beneficial for grazers. Thus, the plant-soil-herbivore interaction presented here should be acknowledged as another feedback mechanism to add to the biogeomorphic feedback that promotes marsh persistence and the existence of alternative stable states.

It is important to understand the extent to which livestock use the entire range of saltmarsh elevations, since it has generally been found that most species of domestic grazers concentrate their activities on higher elevations of the salt marsh (Kiehl and others 1996; Esselink and others 2002; Nolte and others 2014, 2017), whereas erosion processes mainly occur lower down in the elevation gradient (Adam 1990). Our movement analysis showed that while cattle used marsh higher elevations more intensively, they also frequently used areas on the mid-marsh with a high concentration of creeks, crossing wide channels $(>1 \mathrm{~m})$ and even using regions of the low marsh (especially the south population, Figure 3). These results highlight the potential for cattle to produce effects on the mid-to-low marsh environment. Moreover, Sharps and others (2017) (using some of the movement data reported here) showed that cattle tend to use the landward edge of salt marshes more intensively early on during the grazing season, but move to lower elevations as the season progresses. It should be noted that at lower elevations, the soil is generally moister, which means that even though the percentage of animal use might be lower, the soil will be more vulnerable to trampling and treading (Esselink and others 2002). Finally, since marshes around the world are also frequently grazed by sheep and horses (Davidson and others 2017), and there are good reasons to think these animals use a wider percentage of the available marsh area (Nolte and Bakker 2014; Nolte and others 2014, 2017; personal observations), there is clear potential for livestock to influence sediment stability on the mid-to-low marsh.

This study investigated the mechanisms whereby marshes may undergo lateral changes, and focused on the interaction between the biotic and abiotic elements that determine saltmarsh erodibility. Two generalisations can be extracted from our results: (1) the importance of taking into account the biological component of biogeomorphic processes, and (2) the prominence of herbivores as initiators of indirect effects through ecosystem engineering. (1) In hydrology, biological parameters are often overlooked in favour of abiotic parameters. As an example, soil grain size has been identified as the main factor in determining erosion rates across saltmarsh biogeographical regions (Allen 1989; Ford and others 2016; Wang and others 2017). Our results suggest that the effect of soil grain size on erosion rates is indirect, determining first the amount of organic matter in the soil, which influences directly and indirectly (through shear stress) the rates of erosion. Hence, biological pathways influence even the most basic mechanisms that determine erosion. (2) Had we only assessed the direct effects of grazing on erosion processes, we would have concluded that herbivores do not influence saltmarsh lateral erodibility. We rather show that livestock do influence saltmarsh erosion processes, but only via indirect pathways mediated by soil mechanical properties and bare soil cover. With this paper, we heed the call made by a recent review on the field of ecohydrology (Westbrook and others 2013), which raised concerns for an imbalance in the field towards plant-based, rather than fauna-based publications, and called for a more inclusive approach to ecohydrology that would lead major breakthroughs. Hence, this paper illustrates the need to take a more holistic view on plant-soil-herbivore interactions, by taking into account the important direct but also the indirect effects of the different biological and geomorphic layers, which can influence both the biotic and abiotic components of ecosystems.

\section{ACKNOWLEDGEMENTS}

We would like to thank Huiwen Ji, Rachel E. Wright, Mollie Duggan-Edwards, Cai J. T. Ladd, Núria Cot Matas, Bet Pagès Cot and Neula for field assistance. We are also thankful to Dr Chris Rolfe and the Cambridge Geography Science Laboratories for grain size analysis; Hilary Ford, Rachel Kingham, Angus Garbutt, Jan Hiddink, Jen Smart and Lucy Mason for discussions about study design, study sites and instruments; James Grace for discussions on the implementation of structural equation models; and two anonymous reviewers for their helpful comments and discussion. We would finally want to thank Natural Resources Wales and Gwynedd Council for issuing the nec- 
essary permits, and to the landowners for granting access to their land. JFP, TJB, SRJ and MWS acknowledge financial support from the Welsh Government and the Higher Education Funding Council for Wales, through the Sêr Cymru National Research Network for Low Carbon, Energy and Environment.

\section{OPEN ACCESS}

This article is distributed under the terms of the Creative Commons Attribution 4.0 International License (http://creativecommons.org/licenses/by/4 $.0 /$ ), which permits unrestricted use, distribution, and reproduction in any medium, provided you give appropriate credit to the original author(s) and the source, provide a link to the Creative Commons license, and indicate if changes were made.

\section{REFERENCES}

Adam P. 1990. Saltmarsh ecology. Cambridge: Cambridge University Press.

Allen JRL. 1989. Evolution of salt-marsh cliffs in muddy and sandy systems: a qualitative comparison of British West-Coast estuaries. Earth Surf Proc Land 14:85-92.

Bakker ES, Pagès JF, Arthur R, Alcoverro T. 2015. Assessing the role of large herbivores in the structuring and functioning of freshwater and marine angiosperm ecosystems. Ecography 38:1-18.

Bakker JP, Deleeuw J, Dijkema KS, Leendertse PC, Prins HHT, Rozema J. 1993. Salt marshes along the coast of The Netherlands. Hydrobiologia 265:73-95.

Barbier EB, Hacker SD, Kennedy C, Kock EW, Stier AC, Silliman BR. 2011. The value of estuarine and coastal ecosystem services. Ecol Monogr 81:169-93.

Bell LW, Kirkegaard JA, Swan A, Hunt JR, Huth NI, Fettell NA. 2011. Impacts of soil damage by grazing livestock on crop productivity. Soil Tillage Res 113:19-29.

Beschta RL, Ripple WJ. 2006. River channel dynamics following extirpation of wolves in northwestern Yellowstone National Park, USA. Earth Surf Proc Land 31:1525-39.

Beschta RL, Ripple WJ. 2016. Riparian vegetation recovery in Yellowstone: the first two decades after wolf reintroduction. Biol Cons 198:93-103.

Butler DR. 1995. Zoogeomorphology: animals as geomorphic agents. Cambridge: Cambridge University Press.

Christianen MJA, van Belzen J, Herman PMJ, van Katwijk MM, Lamers LPM, van Leent PJM, Bouma TJ. 2013. Low-canopy seagrass beds still provide important coastal protection services. PLOS ONE 8:e62413.

Christianen MJA, Herman PMJ, Bouma TJ, Lamers LPM, Van MM, Van Der Heide T, Mumby PJ, Silliman BR, Engelhard SL, Van MM, Kerk D, Kiswara W, Van De Koppel J, Van Katwijk MM, Van De Kerk M. 2014. Habitat collapse due to overgrazing threatens turtle conservation in marine protected areas. Proc R Soc B 281:20132890.

Cooper NJ, Cooper T, Burd F. 2001. 25 years of salt marsh erosion in Essex: Implications for coastal defence and nature conservation. J Coast Conserv 7:31-40.
D'Alpaos A. 2011. The mutual influence of biotic and abiotic components on the long-term ecomorphodynamic evolution of salt-marsh ecosystems. Geomorphology 126:269-78.

Daleo P, Alberti J, Pascual J, Canepuccia A, Iribarne O. 2014. Herbivory affects salt marsh succession dynamics by suppressing the recovery of dominant species. Oecologia 175:335-43.

Davidson KE, Fowler MS, Skov MW, Doerr SH, Beaumont N, Griffin JN. 2017. Livestock grazing alters multiple ecosystem properties and services in salt marshes: a meta-analysis. Bennett J, editor. J Appl Ecol 54:1395-405.

Deguines N, Brashares JS, Prugh LR. 2016. Precipitation alters interactions in a grassland ecological community. J Anim Ecol $86: 262-72$.

Elschot K, Bouma TJ, Temmerman S, Bakker JP. 2013. Effects of long-term grazing on sediment deposition and salt-marsh accretion rates. Estuar Coast Shelf Sci 133:109-15.

Esselink P, Fresco LFM, Dijkema KS. 2002. Vegetation change in a man-made salt marsh affected by a reduction in both grazing and drainage. Appl Veg Sci 5:17-32.

Ford H, Garbutt A, Ladd C, Malarkey J, Skov MW. 2016. Erosion stabilisation linked to plant diversity and environmental context in coastal grasslands. J Veg Sci 27:1-10.

Foster CN, Barton PS, Lindenmayer DB. 2014. Effects of large native herbivores on other animals. J Appl Ecol 51:929-38.

Francalanci S, Bendoni M, Rinaldi M, Solari L. 2013. Ecomorphodynamic evolution of salt marshes: experimental observations of bank retreat processes. Geomorphology 195:53-65.

Ghebreiyessus YT, Gantzer CJ, Alberts EE, Lentz RW. 1994. Soil erosion by concentrated flow: shear stress and bulk density. Trans ASAE 37:1791.

Grace JB. 2006. Structural equation modeling and natural systems. New York: Cambridge University Press.

Grace JB, Anderson M, Olff H, Scheiner SM. 2010. On the specification of structural equation models for ecological systems. Ecol Monogr 80:67-87.

Grace JB, Scheiner SM, Schoolmaster DR Jr. 2015. Structural equation modeling: building and evaluating causal models: Chapter 8. Ecological statistics: contemporary theory and application. Oxford, UK: Oxford University Press. p 168-99.

Hall K, Boelhouwers J, Driscoll K. 1999. Animals as erosion agents in the alpine zone: some data and observations from Canada, Lesotho, and Tibet. Arct Antarct Alp Res 31:436-46.

Hamza MA, Anderson WK. 2005. Soil compaction in cropping systems: A review of the nature, causes and possible solutions. Soil Tillage Res 82:121-45.

Hickin EJ. 1984. Vegetation and river channel dynamics. Can Geogr/Le Géographe canadien 28:111-26.

Hill MO. 2015. TABLEFIT version 2.0 for identification of vegetation types.

Hobbs NT. 1996. Modification of ecosystems by ungulates. J Wildl Manag 60:695-713.

Hood GA, Larson DG. 2015. Ecological engineering and aquatic connectivity : a new perspective from beaver-modified wetlands. Freshw Biol 60:198-208.

House C, May V, Diaz A. 2005. 15. Sika Deer trampling and saltmarsh creek erosion: preliminary investigation. Proc Mar Sci 7:189-93.

Huey RB, Kearney MR, Krockenberger A, Holtum JA, Jess M, Williams SE. 2012. Predicting organismal vulnerability to cli- 
mate warming: roles of behaviour, physiology and adaptation. Philos Trans R Soc Lond B Biol Sci 367:1665-79.

IPCC. 2013. Climate change 2013: The physical science basis. Contribution of Working Group I to the Fourth Assessment Report to the Intergovernmental Panel on Climate Change.

Jones CG, Lawton JH, Shachak M. 1994. Organisms as ecosystem engineers. Oikos 69:373-86.

Kearney MS, Rogers AS, Townshend JRG, Rizzo E, Stutzer D, Stevenson JC, Sundborg K. 2002. Landsat imagery shows decline of coastal marshes in Chesapeake and Delaware Bays. Eos Trans Am Geophys Union 83:173.

Kiehl K, Eischeid I, Gettner S, Walter J. 1996. Impact of different sheep grazing intensities on salt marsh vegetation in northern Germany. J Veg Sci 7:99-106.

Kingham R. 2013. The Broad-Scale Impacts of Livestock Grazing on Saltmarsh Carbon Stocks.

Kranstauber B, Kays R, LaPoint SD, Wikelski M, Safi K. 2012. A dynamic Brownian bridge movement model to estimate utilization distributions for heterogeneous animal movement. J Anim Ecol 81:738-46.

Kranstauber B, Smolla M. 2016. Move: visualizing and analyzing animal track data. R Package Version 1:r365.

Lefcheck JS. 2016. piecewiseSEM: piecewise structural equation modelling in $\mathrm{r}$ for ecology, evolution, and systematics. Methods Ecol Evol 7:573-9.

Lowe JA, Howard TP, Pardaens A, Tinker J, Holt J, Wakelin S, Milne G, Leake J, Wolf J, Horsburgh K, Reeder T, Jenkins G, Ridley J, Dye S, Bradley S. 2009. Marine and coastal projections. In: UK Climate Projections science report. pp 21-35.

Magilligan FJ, Mcdowell PF. 1998. Stream channel adjustments following elimination of cattle grazing. J Am Water Resour Assoc 33:867-78.

Micheli ER, Kirchner JW. 2002. Effects of wet meadow riparian vegetation on streambank erosion. 2. Measurements of vegetated bank strength and consequences for failure mechanics. Earth Surf Proc Land 27:687-97.

Mosepele K, Moyle PB, Merron GS, Purkey DR, Mosepele B. 2009. Fish, floods, and ecosystem engineers: aquatic conservation in the Okavango Delta, Botswana. Bioscience 59:5364.

Murray BA, Paola C. 2003. Modelling the effect of vegetation on channel pattern in bedload rivers. Earth Surf Proc Land 28:131-43.

Murray NJ, Clemens RS, Phinn SR, Possingham HP, Fuller RA. 2014. Tracking the rapid loss of tidal wetlands in the Yellow Sea. Front Ecol Environ 12:267-72.

Mwendera EJ, Saleem MAM. 1997. Hydrologic response to cattle grazing in the Ethiopian highlands. Agr Ecosyst Environ 64:33-41.

Naiman RJ, Rogers KH. 1997. Large animals and system level characteristics in river corridors. Bioscience 47:521-9.

Nolte S, Bakker JP. 2014. Grazing as a nature-management tool: the effect of different livestock species and stocking densities on salt-marsh vegetation and accretion.

Nolte S, Esselink P, Bakker JP, Smit C. 2015. Effects of livestock species and stocking density on accretion rates in grazed salt marshes. Estuar Coast Shelf Sci 152:109-15.

Nolte S, Esselink P, Smit C, Bakker JP. 2014. Herbivore species and density affect vegetation-structure patchiness in salt marshes. Agr Ecosyst Environ 185:41-7.
Nolte S, van der Weyde C, Esselink P, Smit C, van Wieren SE, Bakker JP. 2017. Behaviour of horses and cattle at two stocking densities in a coastal salt marsh. J Coast Conserv 21:369-79.

Paramor OAL, Hughes RG. 2004. The effects of bioturbation and herbivory by the polychaete Nereis diversicolor on loss of saltmarsh in south-east England. J Appl Ecol 41:449-63.

Powell RA. 2000. Animal home ranges and territories and home range estimators. In: Fuller TK, Boitani L, Eds. Research techniques in animal ecology. Controversies and consequences. New York: Columbia University Press.

Pringle RM, Young TP, Rubenstein DI, McCauley DJ. 2007. Herbivore-initiated interaction cascades and their modulation by productivity in an African savanna. Proc Natl Acad Sci USA 104:193-7.

Prugh LR, Brashares JS. 2012. Partitioning the effects of an ecosystem engineer: Kangaroo rats control community structure via multiple pathways. J Anim Ecol 81:667-78.

R Development Core Team. 2017. R: a language and environment for statistical computing. R Foundation for Statistical Computing, Vienna. http://www.R-project.org. Accessed 26 Oct 2012.

Rodwell JS, Ed. 2000. British plant communities, Vol. 5Cambridge, UK: Cambridge University Press.

Russell JR, Betteridge K, Costall DA, Mackay AD. 2001. Cattle treading effects on sediment loss and water infiltration. $J$ Range Manag 54:184-90.

Scheffer M. 2009. Critical transitions in nature and society. Princeton, New Jersey, USA: Princeton University Press.

Schrama M, Heijning P, Bakker JP, van Wijnen HJ, Berg MP, Olff H. 2013. Herbivore trampling as an alternative pathway for explaining differences in nitrogen mineralization in moist grasslands. Oecologia 172:231-43.

Sharps E, Smart J, Mason LR, Jones K, Skov MW, Garbutt A, Hiddink JG. 2017. Nest trampling and ground nesting birds: quantifying temporal and spatial overlap between cattle activity and breeding redshank. Ecol Evol 7:6622-33.

Shipley B. 2009. Confirmatory path analysis in a generalized multilevel context. Ecology 90:363-8.

Silliman BR, Van De Koppel J, Bertness M, Staunton L, Mendehelsson I. 2007. Drought, Snails, and Large Scale Die Off of U.S. Southern Salt Marshes. 21st Annual Meeting of the Society for Conservation Biology.

Silliman BR, Ziemann J. 2001. Top-down control of Spartina alterniflora production by periwinkle grazing in a Virgina salt marsh. Ecology 82:2830-45.

Simon A, Collison A. 2002. Quantifying the mechanical and hydrologic effects of riparian vegetation on streambank stability. Earth Surf Proc Land 27:527-46.

Skilleter GA, Wegscheidl C, Lanyon JM. 2007. Effects of grazing by a marine mega-herbivore on benthic assemblages in a subtropical seagrass bed. Mar Ecol Prog Ser 351:287-300.

Sørensen LI, Mikola J, Kytöviita MM, Olofsson J. 2009. Trampling and spatial heterogeneity explain decomposer abundances in a sub-arctic grassland subjected to simulated reindeer grazing. Ecosystems 12:830-42.

Stavi I, Lavee H, Ungar ED, Sarah P. 2009. Ecogeomorphic feedbacks in semiarid rangelands: a review. Pedosphere 19:217-29.

Trimble SW, Mendel AC. 1995. The cow as a geomorphic agent A critical review. Geomorphology 13:233-53. 
van Belzen J, van de Koppel J, Kirwan ML, Van Der Wal D, Herman PMJ, Dakos V, Kefi S, Scheffer M, Guntenspergen GR, Bouma TJ. 2017. Vegetation recovery in tidal marshes reveals critical slowing down under increased inundation Jim. Nat Commun 8:15811.

van Klink R, Schrama M, Nolte S, Bakker JP, WallisDeVries MF, Berg MP. 2015. Defoliation and soil compaction jointly drive large-herbivore grazing effects on plants and soil arthropods on clay soil. Ecosyst 18:671-85.

Van de Koppel J, van der Wal D, Bakker JP, Herman PMJ. 2005. Self-organization and vegetation collapse in salt marsh ecosystems. Am Nat 165:E1-12.

van Wesenbeeck BK, van de Koppel J, Herman PMJ, Bertness MD, van der Wal D, Bakker JP, Bouma TJ. 2008. Potential for sudden shifts in transient systems: distinguishing between local and landscape-scale processes. Ecosystems 11:1133-41.
Wang C, Temmerman S. 2013. Does biogeomorphic feedback lead to abrupt shifts between alternative landscape states?: An empirical study on intertidal flats and marshes. J Geophys Res Earth Surf 118:229-40.

Wang H, Van Der Wal D, Li X, Van Belzen J, Herman PMJ, Hu Z, Ge Z, Zhang L, Bouma TJ. 2017. Zooming in and out : scaledependence of extrinsic and intrinsic factors affecting salt marsh erosion. J Geophys Res Earth Surf 122(7):1455-70.

Westbrook CJ, Veatch W, Morrison A. 2013. Is ecohydrology missing much of the zoo? Ecohydrology 6:1-7.

Zuur AF, Ieno EN, Walker N, Saveliev AA, Smith GM. 2009. Mixed effects models and extensions in ecology with R. New York, NY: Springer. 